\title{
JORGE, UM BRASILEIRO: HERÓI ABSURDO OU PASSAGEIRO DA ESPERANÇA?
}

\author{
Melânia Silva de Aguiar \\ UFMG
}

Em "O existencialismo é um humanismo", Sartre conta a história de um jovem que o procura para aconselhar-se sobre uma decisão importante que deveria tomar:

"Vindo procurar-me - diz Sartre - ele sabia a resposta que eu lhe daria, e eu só tinha uma única resposta: você é livre, escolha; isto é, invente. Nenhuma moral geral poderá indicar-lhe o caminho a seguir; não existem sinais no mundo. Os católicos argüirão: sim, existem sinais. Admitamos que sim; de qualquer modo, ainda sou eu mesmo que escolho o significado que têm".

E na mesma ordem de idéias: 
"(...) escolher o conselheiro é ainda engajar$\mathrm{se}^{\prime \prime} .1$

Esta passagem, que expressa um dos pontoschave da filosofia existencialista, transposta para a presente situação, poderá muito bem:

$1^{\text {o }}$ - ilustrar o objetivo deste trabalho sobre Jorge, um brasileiro, de Oswaldo França Júnior;

$2^{\text {o }}$ - lançar alguma luz sobre os motivos da escolha deste livro, como objeto de análise;

$3^{\text {o }}$ - denunciar, de saída, o relativismo de toda interpretação, já que a "escolha" ou "recusa" de sinais pressupõe sempre um limitação subjetiva;

$4^{\circ}$ - funcionar como índice de um tipo de filosofia que teve o seu peso e importância em obras aqui consideradas.

Dando aqui ao termo "sinais" o sentido abrangente que parece ter sido o adotado por Sartre, entenderemos a obra de arte e, particularmente, a obra literária como um sistema de significação que se manifesta por sinais ou por um encadeamento de signos. $O$ objetivo deste estudo é isolar alguns destes sinais, na nossa perspectiva os mais relevantes para a compreensão do significado maior da obra. Como bem observa Umberto Eco,

"Isolar algumas estruturas significantes numa obra é reconhecer essas estruturas como as mais pertinentes em relação às idéias que nos propomos expor sobre essa obra, é já nos situarmos dentro de uma perspectiva interpretativa". ${ }^{2}$

Assim, ainda para Umberto Eco, a análise "dos signos contidos na obra torna-se, inevitavelmente, a verificação de hipóteses ao mesmo tempo históricas e sociológicas e estará carregada de subjetividade". O método "circular", possibilitando o trânsito do contexto social (externo) para o contexto (interno) da obra em questão, revelando as homologias entre os dois, atenuará este condicionamento inicial e poderá ser fonte de compreen-

1. SARTRE, 1987. p.1.

2. ECO, 1976. p.182. são da obra, excluídas as relações de causalidade de um para outro contexto. ${ }^{3} \mathrm{Na}$ obra analisada, procuraremos depreender os sinais retóricos, se é que existem, que encaminhem um ou outro significado global da obra a partir da visão e da linguagem do narrador, a personagem Jorge, centro e objeto da narração.

Ao questionar - "herói absurdo ou passageiro da esperança?" - já situamos historicamente nossa perspectiva analítica no contexto de uma série literária que transfere ao herói a problematicidade individual nascida do confronto com uma sociedade de valores degradados em que se sente deslocado e estranho, daí nascendo a sensação da absurdidade de seu próprio estar-no-mundo. Por "passageiro da esperança", não somente se entende "o que transita", "o homo viator", "o que viaja no bonde da esperança", mas também "o que passa a esperança", alçando-se em símbolo desta esperança social e metafísica. O ensaio "A esperança e o absurdo na obra de Franz Kafka", de Albert Camus, presente em seu livro $O$ mito de Sísifo, polarizando através da obra de Kafka este antagonismo, ilustra o binarismo instaurado em nosso título. ${ }^{4}$

A escolha desta obra e não de outros livros, autores ou assuntos da literatura brasileira pode explicar-se, ainda, segundo o pensamento acima de Sartre, pelo conhecimento prévio ou suposição, pelo menos, da resposta que a obra daria, já que muitas leituras precederam a que deu origem a este trabalho e pelo interesse que tenho neste tipo de resposta. $O$ fato de ser um livro com tiragem de pelo menos uma edição por ano, ou seja, mais de 150.000 cópias vendidas no Brasil (em termos brasileiros, obra vitoriosa, portanto), a par de um quase que desconhecimento da crítica especializada, faz de Jorge, um brasileiro obra para estudos mais ou menos originais; não constitui, entretanto, este fato a principal motivação da escolha, se bem tenha tido o seu peso suplementar, ao lado

\section{Ibidem, p. 183.}

4. Este estudo de Camus, publicado pela primeira vez na revista L'Arbalète, em 1943, não consta da primeira ediçãa de Le mythe de Sisyphe (Gallimard, 1942) tendo sido anexado posteriormente. 
de outros certamente menos relevantes. $O$ que orientou essa escolha, nascida da leitura que há anos venho fazendo dos livros de Oswaldo França Júnior (e ele publicou 14, a começar de $O$ viúvo, de 1965, seu livro de estréia e De Ouro e de Amazônia, de 1989 , obra póstuma) ${ }^{5}$, foi o enorme desprazer que a leitura de seus livros me proporcionam sempre. Não tendo tendências sado-mazoquistas, é curioso como pude permanecer fiel a esta leitura, o que só se explica pela tentativa teimosa de entender a razão do desprazer e do desconforto, aliada à prática profissional, que acaba se tornando uma segunda natureza. $O$ filme de Paulo Thiago, baseado no livro, pôde de certa forma responder a esta questão que sempre me coloquei, confirmando a validade do método comparativo e sua presença permanente em qualquer tipo de pesquisa ou conhecimento da realidade: os seres existem em situação e em permanente confronto, o que lhes determina o modo de ser e seu significado possivel. Por outro lado, a presença de certos traços que se repetem com maior ou menor ênfase em obras como as de Sartre, Camus, Kafka, Borges e, mais recentemente, Onetti, entre outras, obras em que a dissolução da personagem (para usar a expressão de Lucien Goldmann), a supremacia crescente do mundo objetual, a aparente frieza e neutralidade narrativa assumem um papel e uma função significativa relevante, instoume ao confronto textual. Particularmente, $O$ mito de Sísifo e $O$ estrangeiro de Camus são tomados para este confronto, o primeiro, sobretudo para melhor articulação do pensamento e da filosofia do escritor. Logo, para esta busca de sentido de Jorge, um brasileiro, contribuíram de forma mais relevante $o$ filme de igual título e obras da modernidade, surgidas num horizonte histórico relativamente próximo ao do livro e que podem guardar com ele alguma proximidade produtiva.

5. Oswaldo França Júnior publicou com regularidade surpreendente sua obra, a saber: $O$ viúvo (1965); Jorge, um brasileiro (1967); Um dia no Rio (1969); O homem de macacão (1972); A volta para Marilda (1974); Os dois irmãos (1976); As lembranças de Eliana (1978); Aqui e em outros lugares (1980); Á procura dos motivos (1982); Passo bandeira (1984); As laranjas iguais (1985); Recordações de amar em Cuba (1986); No fundo das águas (1987); De ouro e de Amazônia (1989).
O romance Jorge, um brasileiro, no plano de sua história, narra a viagem da personagem Jorge a um ponto definido e seu retorno ao ponto de partida, em função de uma missão que deverá realizar no espaço de uma semana, incluídas aí as duas etapas da viagem. A descrição da viagem, das personagens, das peripécias e dos obstáculos transpostos já na ida, e mais dificultosamente, na volta, chega ao leitor pela visão do narrador de primeira pessoa que tece uma realidade perfeitamente homóloga à de uma classe social, fortemente fincada no histórico, num tempo e num espaço brasileiros, com todas as relações de coerência e verossimilhança desejáveis. Sem entrar no nível da discussão do postulado de Auerbach, ou seja, "o realismo se caracteriza pelo grau de coerência entre o caráter do personagem e o destino que lhe toca", devo admitir que, além desta coerência interna com que se pretende caracterizar o realismo, apresenta-se a personagem aqui focalizada dotada de uma coerência externa, porquanto homóloga ao terreno dos "possíveis" seres sociais (já agora no plano do referencial) que o teriam inspirado. Esta última coerência, a externa, não é de se estranhar, se considerarmos como correta a hipótese levantada por Goldmann de que "o romance é, em épocas diversas, a transposição para o plano literário da vida quotidiana na sociedade individualista nascida da produção para o mercado", ou ainda, "de todas as formas literárias, a mais imediata e diretamente vinculada às estruturas econômicas, na acepção estrita do termo, às estruturas da troca e da produção para o mercado". ${ }^{6}$ Entretanto, ao dar forma a sua personagem, Oswaldo França Júnior nos propõe uma outra realidade que, não sendo simplesmente a reprodução da vida social ou econômica que a inspira, dilui ou apaga dela os sinais indicadores de um possivel sentido "social", ou dos valores sobre os quais se funda e que costumam funcionar como marcos ou sinalizadores éticos e de comportamento. Assim, ao realizar sua viagem com o objetivo de cumprir a tarefa que lhe foi confiada, inicialmente só e depois com suas carretas, ao atravessar o espaço inóspito das chu-

6. GOLDMANN, 1967, p.175 
vas, das pontes destruídas e das barreiras humanas e naturais, Jorge é atravessado por uma crescente tomada de consciência da absurdidade de sua ação, indiciada esta tomada de consciência já no início da viagem pela raiva que se apossa dele, sem que ele próprio saiba explicar exatamente por quê, e concluída no final da ação, quando, circularmente, volta ao espaço inicial, à sala em que está Helena, a mulher do patrão. Esta tomada de consciência, no entanto, não se dá por obra de sinais exteriores que o alertem ou o esclareçam em sua trajetória. Os comentários de Sandra e Altair, a alusão maliciosa de um "caroneiro" ("- É, quem tem isso tudo não precisa viajar, não é?" $)^{7}$, o próprio desfecho da história são narrados de forma discreta demais para que, ao nível da narrativa, possam significar um fator determinante na construção do novo Jorge que se vai fazendo no transcorrer do relato. Esta construção se faz internamente e em silêncio e, sobretudo, mediante o choque final do confronto com os valores do patrão, representando aí uma sociedade que vê no lucro seu principal fim e nos seres e objetos, ainda segundo a terminologia de Goldmann, seu "valor de troca". Jorge, fundamentando seu compromisso com. Mário, o de trazer as carretas no prazo estipulado, numa relação de amizade, já que em outros tempos tinham sido companheiros, preocupado todo o tempo com o prejuízo a que estaria sujeito o "amigo" caso as carretas não chegassem a tempo, só no final de sua viagem percebe a diferença da moeda sobre a qual se assenta sua ligação com o patrão. Voltando ao ponto de partida, na data aprazada, ele na verdade não volta ao ponto de partida: ao encontrar uma nova situação (há ordens para que ele não mais durma na garagem, o contador exige-lhe, fora do costume, uma prestação de contas, ele não consegue encontrar o patrão, tudo está transformado - até mesmo o sol brilha - ele renovado), conclui aí seu processo de transformação, perfeitamente expressa na frase final do livro, dirigida a um interlocutor invisível: "Porque, você sabe, a gente não consegue ficar conversando muito tempo, sem no fim

7. FRANÇA JÚNIOR, 1976. p.159. falar do que a gente fez, do que a gente foi."

Chama particular atenção a ausência ou diluição da colocação explícita dos valores individuais e da vida social tal como ela se estrutura no romance: os que chegam a manifestar-se do lado da personagem e seus companheiros de viagem, como o companheirismo e a solidariedade do trabalho conjunto, o sentido do compromisso e da palavra assumida, a noção de responsabilidade, o esforço e a capacidade de enfrentar obstáculos, são narrados sem a ênfase e o entusiasmo retóricos próprios da narrativa tradicional e sem a intermediação judiciosa do narrador. A gratuidade de que se revestem estas ações parece destituí-las de qualquer valor, já que o fim a que se propõem não conduz efetivamente a nada, funcionando esta gratuidade como índice de alienação e inconsciência. A intermediação de outras personagens mais "esclarecidas", apontando o outro lado, questionando o por quê e o móvel das ações, apaga-se no texto, por seu desaparecimento gradual, até mesmo no plano da memória (o caso de Sandra, de Altair etc.).

Em compensação, ganha relevo particular a descrição minuciosa dos objetos, dos encontros e conversas secundárias, das relações de superfície, das situações externas, das histórias paralelas e infindáveis, nascidas umas das outras, repetidas à exaustão e sem uma função aparentemente significativa na seqüência narrativa. Jorge, a personagem central, recupera pela memória vários trechos de sua vida, isolados e sem um nexo forte que os ligue; o tempo em que se inserem é descontínuo, fragmentado; dependuram-se no fio temporal da narrativa, como excrescências mais ou menos inúteis. Figuras vêm e vão, aleatoriamente, saem da história como entraram, pouco ou nada dizendo, dentro ainda da mesma atmosfera de gratuidade que só não chega ao "non sense" pelo sentido de realidade e coerência que, tomados isoladamente, transmitem. A gratuidade parece ser assim o índice maior da falta de sentido das ações vistas na articulação global do texto.

8. Ibidem, p.188. 
Por outro lado, colocando-se estritamente nos limites de sua observação e vivência pessoal, o narrador, "reinventando" bastante conscientemente a linguagem de um caminhoneiro, somente interfere no curso de sua ou suas histórias, para emitir algum juízo ou opinião, quando é afetado em seus "sentimentos de superfície": alegra-se com o Altair e sua família, irrita-se com os sócios do Mário, de Brasilia, espanta-se na estrada com a visão da mulher sem nariz, admira o asseio do Toledo, diverte-se com a história da D. Olga etc. Conhece-se muito mais a personagem por suas ações exteriores e sensações de "flor da pele" do que por suas inquietações, que aparentemente não tem, ou manifestações de sentimentos mais complexos. No entanto, toda uma profunda transformação se processa em seu interior sem que a linguagem dela dê sinais. Se esta parcimônia verbal ou retórica é perfeitamente coerente com o nível e o extrato social da personagem, inegavelmente ela é indício de outro fenômeno, não rigorosamente social, mas tecido no interior do próprio discurso, falando através de sua ausência e servindo às intenções do autor.

Sem querer filiar o romance de Oswaldo França Júnior ao "nouveau roman" francês, mas vendo entre eles pontos em comum, faço-me o questionamento de Alain Robbe-Grillet, quando se refere aos grandes romances do século XIX por oposição aos seus próprios e que podem também aqui se opor ao romance que nos ocupa:

"Quem descreve o mundo nos romances de Balzac? Quem é esse narrador onisciente, onipresente, que se coloca em todo lugar ao mesmo tempo, que vê simultaneamente o avesso e o direito das coisas, que segue ao mesmo tempo os movimentos dos rostos e os das consciências, que conhece ao mesmo tempo o presente, o passado e o futuro de toda a aventura? Só pode ser um Deus.

É só esse Deus que pode pretender ser objetivo. Enquanto que em nossos livros, pelo contrário, é um homem que vê, que sente, que imagina, um homem situado no espaço e no tempo, condicionado por suas paixões, um homem como você e eu. E o livro não conta nada além de sua experiência, limitada, incerta. É um homem daqui, um homem de agora, que é enfim seu próprio narrador". 9

Para Nathalie Sarraute, a maneira como a realidade se apresenta nas obras dos grandes escritores do passado é fruto de uma pesquisa obstinada que lhes permitiu pela primeira vez "pôr à luz do dia uma parte ainda intacta do mundo invisível".10 Novas pesquisas conduzirão à descoberta de novas realidades, levando ao afastamento de formas usadas que já não expressam a realidade "desconhecida". Para a escritora, a realidade da obra literária é, portanto, uma revelação e uma questão de forma, fruto de pesquisa ao mesmo tempo da realidade "externa" e das formas de linguagem.

Na obra de Oswaldo França Júnior, há a proposta de uma linguagem, que tenta ser a mais natural possível, entendendo-se por natural a linguagem destituída de artifícios e ao máximo "fiel" a um determinado modelo que pretende reproduzir ou evocar. Evidentemente, a linguagem do livro não é a de um caminhoneiro (entre outras coisas porque a perfeita transposição do código oral para o escrito é impossível e porque, afinal, o que é a linguagem de um caminhoneiro?), mas é como se fosse. Artificiosamente o autor cria uma linguagem que evoca a de um grupo de indivíduos reunidos sob o rótulo "caminhoneiro", "motorista" ou algo assim; linguagem bastante limitada em suas possibilidades de seleção vocabular e de articulação sintagmática, mas, sobretudo, linguagem artificiosamente criada para explicitar a sua falta de artifícios, de recursos subjetivos de expressão, a apontar antes para o seu valor coletivo e destituído das marcas de uma intenção sinalizadora de significados individualmente adotados; além do mais, uma linguagem "inocente" (como se isso fosse inteiramente possível), imune às pegadas da ideologia. Entre o recurso de um pretenso pintor de que nos fala Jakobson, que para evitar a ambi-

9. ROBBE-GRILLET, 1969. p.92-3.

10. SARRAUTE,(s.d.). p. 145. 
ENSAIO

güidade da representação "se expôs a si mesmo como nu artístico" e a solução mais convencional de "empregar elementos tão cristalizados que a comunidade não mais os pensa como artifícios, isto é, como elementos do código"11, Oswaldo França Júnior fica com a segunda, e a "naturalidade" (entre aspas), de sua linguagem, pela ausência de sinais individualizadores, transmite a sensação de falta, de vazio, de neutralidade descompromissada.

Em O grau zero da escritura, Barthes, recorrendo ao conceito de termo neutro ou termo-zero da lingüística, ou seja, a existência "entre os dois termos de uma polaridade (singular-plural, pretérito-presente), de um terceiro termo, termo neutro ou termo-zero"12, estabelece uma comparação entre este conceito e a "escritura de grau zero", no fundo, "uma escritura indicativa ou, se se quiser, amodal". Esta escritura neutra, "escrita branca",13 como ele chama em outro passo, que ele dá como característica dos escritores mais representativos da modernidade, é feita da ausência de "julgamentos", e mais:

"Essa fala transparente, inaugurada por $O$ estrangeiro de Camus, realiza um estilo da ausência que é quase uma ausência ideal do estilo; a escritura se reduz então a uma espécie de modo negativo no qual os caracteres sociais ou míticos de uma linguagem são abolidos em benefício de um estado neutro e inerte da forma; o pensamento conserva assim toda a sua responsabilidade, sem revestir-se do engajamento acessório da forma numa História que não lhe pertence."

\section{E ainda:}

"(...), desta vez, o instrumento formal não está mais a serviço de uma ideologia triunfante; ele é o modo de uma situação nova do escritor, é a maneira de existir de um silêncio; perde voluntariamente qualquer re-

\footnotetext{
11. JAKOBSON, 1965. p.34.

12. BARTHES, 1971. p.91.

13. Ibidem, p.14.
}

curso à elegância ou à ornamentação, pois essas duas dimensões introduziriam novamente o Tempo na escritura, isto é, uma potência derivante, portadora de História."14 A fala "transparente" e "descompromissada" de $O$ estrangeiro, instaurando um mal-estar novo na literatura ocidental, a que se cola a idéia do absurdo e da falta de sentido da existência humana, encontra em o Mito de Sisifo, escrito durante a guerra e publicado em 1942, sua formulação teórica, a que não falta a contribuição dos filósofos existenciais, a quem Camus critica e admira. Encontra-se aí na verdade a primeira proposição da noção de "absurdidade", ou seja, da tomada de consciência pelo ser humano da falta de sentido de sua condição. Retomando o mito de Sísifo para simbolizar o absurdo da existência humana, Camus se detém em dois de seus elementos: a gratuidade do trabalho executado por Sísifo, escalando o rochedo e fazendo rolar ao infinito a pedra que dele se despenha, com toda a sua carga de absurdo ("não existe punição mais terrível do que o trabalho inútil e sem esperança") e a consciência deste absurdo, revelada no momento do retorno à planicie em busca novamente da pedra, "ad aeternum". Considerando o absurdo uma "doença do espírito" que se encontra esparsa em nosso século, o oposto de todas as certezas e de tudo o que a "razão cega" pretende afirmar como claro, imagina-o nascido "desse confronto entre o apelo humano e o silêncio despropositado do mundo". Sobre o conhecimento pergunta-se:

"De quem e de que, de fato posso dizer 'conheço isso?'

Este coração, em mim, posso experimentálo e julgo ainda que ele existe. Pára aí toda a minha ciência, o resto é construção."15

Sobre a moral, considera que pode haver "responsáveis"; "culpados" nunca, já que

"todas as morais são baseadas na idéia de que um ato tem conseqüências que o legiti-

14. BARTHES, 1971. p.93.

15. CAMUS, 1989. p.38. 
mam ou o obliteram. Um espírito sensibilizado pelo absurdo julga apenas que esses desdobramentos devem ser considerados com serenidade." 16

Negando-se a admitir qualquer esperança que advenha da noção de Deus ou de uma vida além da morte, Camus critica com veemência os filósofos que, tocados pelo absurdo, buscaram em Deus ou em qualquer "aspiração ao eterno" o consolo ou a explicação do inexplicável: Jaspers, Kierkegaard, Chestov... Levando até o fim as conseqüências de sua lógica, reconhece que o absurdo (esta "náusea", como o quer Sartre, por ele lembrado) ${ }^{17}$, "estado metafísico do homem consciente", pressupōe "a ausência de toda esperança (que não tem nada a ver com o desespero), a recusa contínua (que não se deve confundir com a renúncia) e a insatisfação consciente (que não acertariamos em associar à inquietação juvenil $)^{\prime \prime} .{ }^{18}$

Falando da obra de arte, considera-a, não uma saida ao absurdo, mas um dos signos desta doença. A propósito dos grandes romancistas, os romancistas filósofos, Balzac, Stendhal, Dostoievski, Proust, Malraux, Kafka, entre outros, por oposição aos "escritores de tese", elogia neles o terem escrito mais em imagens do que em raciocínios, persuadidos "da inutilidade de todo princípio de explicação e convencidos da elucidativa mensagem da aparência sensivel". Outra das qualidades apontadas por Camus à obra de arte e, por extensão, ao romance é a sua gratuidade:

"Se as exigências do absurdo não são nela respeitadas, se ela não ilustra o divórcio e a revolta, se se conforma às ilusões e desperta a esperança, já não é gratuita. não posso mais me separar dela. Minha vida pode encontrar ali um sentido: isso é desprezível."19

Em $O$ estrangeiro, Camus transfere para o narra-

\footnotetext{
16. Ibidem, p.86

17. A náusea, publicado em 1938 , precede, portanto, de quatro anos $O$ mito de Sísifo. É inegável a influência de Sartre sobre Camus, apesar da ruptura, posterior.

18. Op. cit. p.50.

19. CAMUS, 1989. p. 123
}

dor, também em primeira pessoa, os traços mais relevantes de seu pensamento: a indiferença lúcida (sinalizada no "tanto faz" repetitivo de Meursault, o narrador, quando the pedem uma opinião ou um juízo), a gratuidade dos gestos e das ações (ele mata um árabe que mal conhece), a ausência da noção de "culpa", a consciência de sua liberdade e o orgulho dela, a não concessão a qualquer esperança, metafísica ou social.

A gratuidade das ações, presente em vários niveis do livro de Oswaldo França Júnior, constitui o eixo central de sua estrutura narrativa e explicita-se no momento da manifestação concreta dos diferentes valores que orientam a ação de Jorge e do patrão. Por amizade ele se sacrifica para evitar o prejuízo de Mário. Só assim seu sacrifício terá um sentido, e ele rolará a pedra tantas vezes quantas for preciso em nome desta "moeda". A instauração da consciência desta gratuidade, que se dá no final da viagem, cumprindo o trato assumido, não se traduz em considerações sobre a ingratidão dos homens ou sobre a injustiça das estruturas sociais. Sua reação é, primeiramente, agredir o contador e, depois, beijar a "distinta" mulher do patrão, únicos sinais de sua mudança. A aparência sensível, a partir de uma experiência pessoal, nos termos de Camus, falará muito mais que qualquer explicação. Transpondo para o plano existencial a experiência da personagem, esta negação ao comentário judicioso (tão frustrante para o leitor ávido de respostas) indica o caráter pessoal e solitário de qualquer forma de tomada de consciência e a luta que forçosamente significará o "atingimento" a seu ponto de chegada.

Sob estes aspectos, nada de mais oposto que o filme Jorge, um brasileiro, dirigido por Paulo Thiago e inspirado no livro de Oswaldo França Júnior ${ }^{20}$ Evidentemente, o compromisso de fidelidade de um cineasta com a obra que o inspira é relativo e, como bem observa Dirce Cortes Riedel, "o cineasta não é tradutor de um autor, mas um novo autor com direitos próprios". ${ }^{21}$ Ao

\footnotetext{
20. Este filme, dirigido por Paulo Thiago, teve roteiro de Alcione Araújo, com participação do diretor.

21. RIEDEL, 1986. p.21-3.
} 
transpor uma obra literária para o cinema - saindo da linguagem puramente verbal para a linguagem sobretudo visual - o cineasta terá não somente de levar em conta as exigências do novo código, como ainda definir para si próprio o grau possível e desejado de fidelidade à obra original. Ele pode desviar-se do roteiro original do livro, criando cenas que, cinematograficamente, rendam mais; pode (e quase sempre deve) suprimir episódios ou detalhes que comprometam o ritmo do filme (ainda que estejam perfeitos na estruturação interna do livro); pode intensificar ou enfraquecer elementos presentes na tessitura de construção do romance, com a intenção deliberada de ressaltar determinada mensagem. As múltiplas sugestões que a leitura de um livro desencadeia proporcionam fatalmente inúmeras interpretações, ressonâncias, imagens mentais, articulações de sentido, vazios a serem preenchidos. A linguagem visual, cinematográfica, unida à linguagem verbal, que também participa ainda que em menor escala do cinematográfico, preenche muitos destes vazios, mas abre, ao mesmo tempo, outros, havendo sempre espaços a serem preenchidos pelo expectador. Exemplo disto é a imagem "vista" no cinema, forma de preenchimento de um vazio, pelo menos inicial, que a forma "mentada" da literatura deixa em aberto. Em compensação, o caráter reflexivo e obsedante de certas narrativas não consegue encontrar seu equivalente cinematográfico. Exemplo deste tipo de dificuldade é o que se verifica com uma passagem do livro, achado verbal impossível de ser recuperado no filme. No episódio em que Jorge, após tomar um banho precário de chuveiro na delegacia de Coronel Fabriciano, a caminho das carretas, em Caratinga, ouve o rádio tocando na sala, há um sujeito que canta "dizendo que era sentimental demais". É notável o uso do chamado discurso indireto nesta frase em que o autor, ignorando o contexto em que se situa a frase melódica - "sentimental eu sou" - na interpretação de um cantor ouvido pelo rádio, identifica o sujeito que canta a este ser sentimental, traduzindo uma neutralidade e indiferença que acaba funcionando como uma espécie de ironia sutil. O filme não tinha como captar este achado, que é verbal, e que está intimamente colado a uma intenção difícil de ser mantida. A solução encontrada no filme não tem nada a ver e mostra como é ilusória a visualização do literário. O filme Jorge, um brasileiro recorre a todos os expedientes acima apontados e a muitos outros mais. Entretanto, pode-se dizer que há um acentuado grau de fidelidade do filme ao livro. Se houve acréscimos, supressões, alterações, substituições de episódios, fusão de personagens, as modificações não chegaram a abalar a história. De certa maneira, até a reforçaram, articulando situações e sublinhando traços psicológicos das personagens que realçaram o caráter épico da obra. Um herói que sai vencedor na luta contra uma natureza inclemente, contra a burocracia da policia federal (como no livro), sai mais herói (e isto só se acha no filme) se se junta a estes obstáculos a hostilidade inicial dos companheiros de viagem, que, no entanto, vão minando sua resistência diante da coragem e obstinação de Jorge, em sua louca viagem de volta. Por outro lado, a gratuidade da ação, geradora do absurdo, não existe no filme, já que Jorge espera ser recompensado pelo patrão com um empréstimo que serviria para participar de um leilão de caminhões realizado pela prefeitura; já próximo à chegada, depois de tantos sacrifícios, desiste de seu compromisso e chega com atraso a Belo Horizonte: sua revolta se faz "por fora", sob o peso do sacrifício e dos comentários dos amigos.

O que, entretanto, afasta substancialmente o filme do livro e que se traduz não no nivel da história nem do estilo ou forma de expressão, é o que responde pelo significado maior do livro, ou seja a deliberada intenção de não apontar significados. A noção de "bem" e "mal" não existe no livro de Oswaldo França Júnior e a luta por um lugar ao sol é a luta pela lúcida consciência dos próprios limites da condição humana. A linguagem sem retórica de Jorge, um brasileiro, além de refletir a possivel linguagem de um possível "brasileiro médio" $^{\prime 22}$ na sua limitação verbal, é também a recusa

22. Em entrevista, Oswaldo França Júnior diz ter-se ex.upenhado em "bolar" a linguagem de um motorista de caminhão, esse "brasileiro médio" (Palácio das Artes, 1987). 
em apresentar verdades prontas e acabadas. $O$ filme de Paulo Thiago é enfaticamente retórico, usado aqui o termo num de seus principais sentidos isto é, o que deriva da Retórica, concebida como a "utilização de recursos da linguagem com finalidades de persuasão".23 O filme propicia ao expectador uma franca tomada de posição, facilita as coisas e neste sentido está muito mais próximo do romance de tese do século XIX do que de uma moderna corrente narrativa que se recusa a ser "consolo ou esperança". No filme, a injustiça de que Jorge é vítima é ressaltada na fala dos companheiros de viagem, nas observações de Altair, nas queixas mais enfáticas de Sandra, no "suspense" da cena do quase afogamento de Fefeu, no impacto do tiro que atingiu o Oliveira, na trilha sonora pontuação o dramático e o lírico, no contraste fotograficamente explorado no final do filme entre as roupas engomadas do patrão e as duras de barro de Jorge, em retórica visual e auditiva aliciante.

Tudo isto está ausente ou atenuado no livro, marcando a meu ver a diferença maior entre livro e filme, diferença que, sem comprometer a superficie da história, instaura pelo menos um modo distinto de filtrar e de conceber a realidade e um profundo distanciamento na concepção do homem enquanto sujeito ou objeto de seu destino, senhor ou escravo de seus limites.

O Jorge do filme, arquitetado pelo cineasta, é na sua trajetória de conscientização social, o símbolo de uma esperança que o filme, em sua retórica maniqueísta, não cansa de apontar; obra de "consolo", portanto, onde encontramos todos os sinais e todas as respostas às nossas angústias.

O Jorge do livro, na sua vitoriosa e gratuita trajetória via à lucidez, espicaçando com seu absurdo e desalojando com sua recusa à sinalização as nossas certezas, é o Sísifo que continuará rolando a sua pedra, orgulhosa e revoltadamente consciente de sua condição, sem amanhã.

\section{REFERENCIAS BIBLIOGRÁFICAS}

1. BARTHES, Roland. O grau zero da escritura. São Paulo : Cultrix, 1971.

2. CAMUS, Albert. $O$ mito de Sésifo. Rio de Janeiro: Guanabara, 1989.

3. DUBOIS, V. Retórica da poesia. São Paulo: Cultrix, 1980.

4. ECO, Umberto. Apocalipticos e integrados. São Paulo:Perspectiva, 1976.

5. FRANÇA JUNIOR, Oswaldo. Jorge, um brasileiro. Rio de Janeiro: José Olympio, 1976.

6. GOLDMANN, Lucien. Sociologia do romance. Rio de Janeiro: Paz e Terra, 1967.

7. JAKOBSON, Roman. Du réalisme artistique. In: TODOROV, T.(org.). Theorie de la littérature. Paris: Ed. du Seuil, 1965 apud LIMA, Luiz Costa. A metamorfose do silêncio. Rio de Janeiro: Eldorado,1974.

8. LIMA, Luiz Costa. A metamorfose do silêncio. Rio de Janeiro: Eldorado, 1974

9. RIEDEL, Dirce Cortes. A hora da estrela; compromisso com a palavra. Rio de Janeiro: UERJ, 1986.

10. ROBBE - GRILLET, Alain. Por um novo romance. São Paulo Documentos, 1969.

11. SARRAUTE, Nathalie. Duas realidades. Cadernos de Cultura, Lisboa, p. 145.

12. SARTE, Jean - Paul. $O$ existencialismo é um humanismo. São Paulo: Nova Cultural, 1987. 
ENSAIO

RÉSUMÉ

"Jorge, um brasileiro", traduction filmique du livre du même titre du romancier Oswaldo França Júnior, dans sa richesse rhétorique rend possible une compréhension plus juste du livre, objet principal de l'analyse comparative des deux systèmes considérés ici. L'absence de signes rhétoriques apparents dans le livre traduit l'installation d'une lucidité qui détruit toutes les certitudes. 